\title{
Trust and Public Support for Environmental Protection in Diverse National Contexts
}

\section{Malcolm Fairbrother}

University of Bristol

Abstract: Worldwide, most people share scientists' concerns about environmental problems, but reject the solution that policy experts most strongly recommend: putting a price on pollution. Why? I show that this puzzling gap between the public's positive concerns and normative preferences is due substantially to a lack of trust, particularly political trust. In multilevel models fitted to two international survey datasets, trust strongly predicts support for environmental protection within countries and, by some measures, among countries also. An influential competing theory holds that environmental attitudes correlate mostly with left versus right political ideology; the results here, however, show that this correlation is weaker and varies substantially from country to country-unlike that with trust. Theoretically, these results reflect that environmental degradation is a collective action problem and environmental protection a public good. Methodologically, they derive from the more flexible application of multilevel modeling techniques than in previous studies using such models.

Keywords: Environmental concern; Public opinion; Trust; Environmental taxes; Multilevel models
Citation: Fairbrother, Malcolm. 2016. "Trust and Public Support for Environmental Protection in Diverse National Contexts." Sociological Science 3: 359-382.

Received: March 3, 2016

Accepted: March 13, 2016

Published: June 8, 2016

Editor(s): Jesper Sørensen, Sarah Soule

DOI: 10.15195/v3.a17

Copyright: (C) 2016 The Author(s). This open-access article has been published under a Creative Commons Attribution License, which allows unrestricted use, distribution and reproduction, in any form, as long as the original author and source have been credited. (C) (i)
W HY doesn't the public want to make polluters pay to pollute? Despite scientists' warnings about the seriousness of environmental problems, public opinion is hostile to the solution to many of those problems that policy experts most strongly recommend: requiring that firms and consumers pay to engage in environmentally damaging activities (Parry, Norregaard, and Heine 2012). This public hostility is discouraging governments from taking action; sometimes major decisions not to enact measures for environmental protection have been a direct consequence (Harrison 2010). In 2014, for example, Australia repealed its carbon tax after voters elected a government that specifically promised to do so; putting a price on greenhouse gas emissions proved similarly unpopular with Canadian voters in 2008; and the Swiss have twice voted in national referenda against increased taxes on polluting energy (Baird 2014; Harrison 2012; Maclucas 2015; Thalmann 2004).

Previous studies have made some progress in understanding the public's hostility towards key policies for environmental protection, but overall environmental attitudes remain poorly understood (Cao et al. 2014; Harrison 2010). The main contribution of this article is to show that public support for putting a price on pollution is largely about trust, particularly political trust. Both social trust and political trust have appeared in some previous studies' lists of statistically significant correlates of support for environmental protection. But, partly because of an overemphasis on statistical rather than substantive significance, the existing literature has largely overlooked the major importance of trust, as well as the specific ways in which trust correlates with environmental attitudes. 
Few previous studies, for example, have distinguished between positive beliefs and concerns about the environment on the one hand and normative preferences on the other. Many studies examine only one or the other, or take their object of study to be generalized "environmental concern," defined expansively to include both the positive "insight that humans endanger the natural environment" and a normative "willingness to protect nature" (Franzen and Vogl 2013:1002; for a similar, widely cited definition, see also Dunlap and Jones 2002:485). Normative preferences for protection are certainly shaped by people's beliefs about the existence of environmental problems and concerns about their seriousness. But this article shows that people's preferences about protection and policy are nowhere near determined by their beliefs and concerns, and trust correlates with preferences much more than with beliefs and concerns-an important distinction not previously identified in the literature.

Theoretically, there is good reason for people's preferences-net of their environmental concern-to reflect social and political trust. As implied by the well-known tragedy of the commons parable, environmental problems arise insofar as people can impose some of the costs of their actions onto others while enjoying the full rewards themselves. Arrangements for environmental protection are beneficial to individuals only if the costs they pay for abatement-higher prices for goods and services-are outweighed by benefits arising from proportionate behavior changes by others. Environmental protection, a public good, therefore requires collective action coordinated by the state. People's support for protection should logically reflect their trust in others to reciprocate their efforts and in the state to implement schemes for environmental protection competently and as promised.

The article presents multilevel analyses of data from two surveys, each conducted in dozens of countries at diverse levels of economic development. Increasing numbers of studies are presenting multilevel analyses of data on environmental attitudes from multiple countries (e.g., Fairbrother 2013; Franzen and Meyer 2010; Gelissen 2007; Givens and Jorgenson 2013; Harring 2013; Jorgenson and Givens 2014; Kvaløy, Finseraas, and Listhaug 2012; Marquart-Pyatt 2012; Pampel 2014). However, few have identified factors that correlate cross-nationally with environmental concern or preferences, whereas this article shows that political trust predicts not only differences across individuals in their support for environmental protection but also differences across countries.

Also, in contrast to most previous studies, this article exploits the multilevel character of international survey data in drawing attention to differences across nations in the individual-level correlates of support for environmental protection. Many previous studies have suggested that support for environmental protection derives from people's broader political ideologies: placement on the left rather than right of the political spectrum and subscription to state-interventionist and/or egalitarian rather than free-market and/or individualistic perspectives and policy preferences. This article shows that this relationship holds in some countries, but not in many others, by using not just multilevel models with random intercepts-a now common approach in the literature-but also more flexible models with random slopes. Notably, the United States is one of those countries where support for environmental protection is stronger among people with more left-of-center, egali- 
tarian, and state-interventionist political ideologies, and a disproportionate number of studies have employed U.S. data. No researcher would suggest explicitly that findings from any one country are likely to apply everywhere. But, in comprising more studies of the United States than any other country and failing to remark on differences between the United States and many other nations, the literature presents a very partial picture. In much of the world, environmental protection is not a left-right issue; if anything, it is a right-left issue.

\section{Tragedies and Trust}

Governments are failing to address many environmental problems because of lobbying by business interests with a stake in the status quo (e.g., Farrell 2016), but they are also disregarding many important environmental policy recommendations because public opinion is hostile. To illustrate, when residents of 32 nations were asked in 2010 how concerned they were about environmental issues generally, the most common answer was 4 on a scale from 1 to 5 . But, when the same people were asked how willing they would be "to pay much higher taxes in order to protect the environment," the most common answer was 1-"very unwilling." (These are results from the International Social Survey Programme, one of the two surveys discussed and analyzed in greater detail below.) So most people believe environmental problems are real and worrying, but they are hostile to what experts regard as the most effective, inexpensive means of addressing them. The main aim of this article is to explain this puzzling divide.

Referring to taxation in a survey question about the environment makes sense not just because it helps gauge people's support for protection. Taxation also occupies an important place theoretically in environmental economics, which recommends attaching a price to pollution or resource use in the case of most environmental problems, even if environmental regulation has historically tended to use more "command-and-control" approaches instead (Prasad 2010; UNEP 2004). In the absence of incentives to the contrary, individuals have reason to act in ways that do not maximize collective human well-being. They engage in activities whose benefits they enjoy, but whose costs they can impose (externalize) to some extent onto others, with costly consequences for society as a whole (including future generations). Environmental protection, conversely, is a solution to this collective action problem (see e.g., Pearce 2002). Research shows that there is some scope for behavior changes that would save individual firms and households money while simultaneously reducing their contributions to many environmental problems (Dietz et al. 2009). Nevertheless, voluntary actions alone are inadequate: firms and households under-supply pollution abatement if the costs they incur individually exceed the benefits they (and society) enjoy from such efforts. Governments therefore need to incentivize more substantial efforts (OECD 2010). There is, therefore, a crucial role for state action in environmental protection. Taxes, or a requirement that polluters buy permits to engage in some polluting or resource-depleting activity, are efficient corrections to the market failures causing environmental problems by attaching a price to activities proportionate to the harms they cause (e.g., Endres 2011). 
From any one individual's point of view, costly abatement efforts are only meaningful insofar as they are offset by proportionate contributions from others, yet such contributions are not guaranteed. Instead of participating in collective efforts to protect the environment, a firm or household could choose to cheat, such as by flouting a financially costly regulation or evading a pollution tax (UNEP 2004). The benefits of a system for environmental protection to any given participant therefore depend on the probability of others' compliance, which in turn depends, to an extent, on the quality of the system's enforcement. Public administrators engaging in only haphazard enforcement could impose significant compliance costs on some polluters, but not others. At an even earlier stage, alternatively, policymakers could design a system with loopholes or put revenues to poor (perhaps corrupt) use.

When assessing the appeal of new green taxes-a framework of collective action for environmental protection-it therefore makes sense for individuals to consider the risks both of cheating by generalized others and of corruption and incompetence on the part of policymakers and public administrators. Not surprisingly, trust in both government and other citizens predicts people's compliance with tax laws generally (Marien and Hooghe 2011; Scholz and Lubell 1998). Why would individuals pay their taxes when (they think) others will not? Conversely, positive compliance is a virtuous circle: when individuals trust others to obey the rules, they are more likely to do so themselves (Ostrom 2010; Sønderskov 2009). The benefits of environmental protection should be greatest, then, in societies with more trust (and more compliance) and, within societies, individuals should be more supportive of collective action for environmental protection insofar as they are trusting. In one even more specific sense, also, the benefits of new green taxes relative to their costs should depend on what governments do with the revenues. Often governments promise to offset new green taxes with cuts to other kinds of taxes, such that the net costs to the individual polluter-taxpayer are modest. In practice, however, people tend to be very skeptical about such promises of revenue neutrality (Dresner et al. 2006; Green Fiscal Commission 2009; Harrison 2012; Lorenzoni, Nicholson-Cole, and Whitmarsh 2007).

In sum, individuals' support for environmental protection is likely to depend on their trust in public authorities to design effective instruments and to implement those instruments as promised and in turn in their confidence that other pollutertaxpayers (or resource users) will play by the rules. For this reason, at local scales, trust is an important foundation for the effective management of common pool resources such as fisheries and groundwater (Ostrom 1999). People who are more trusting also tend to contribute more to environmental public goods by recycling, conserving water, using public rather than private transport, and buying green products (see Irwin and Berigan 2013 for a review).

\section{Previous studies of trust and support for environmental protection}

Attitudinally, previous studies have noted a correlation between trust and support for environmental protection, but none have clearly demonstrated the strength and nature of the relationship. Some studies have examined the correlates of broader "environmental concern," such as Franzen and Vogl (2013), who also analyze the 
2010 ISSP dataset considered here. The results they present are difficult to interpret, however. Despite finding that ten different survey questions capture at least two distinct dimensions of generalized environmental concern, they present only models of an index comprising all at once. An alternative approach, such as that used by Dunlap and York (2008), is to examine separate indices of "willingness to make economic sacrifices" and "perceived seriousness of environmental problems." Adopting this approach, I will use "concern" to refer only to a belief specifically in the existence of environmental changes that are both harmful and large-scale. In the analyses below, I show empirically that trust relates very differently to "concern" in this positive, narrower sense, as compared to normative support for doing something about environmental problems.

Franzen and Vogl (2013) also fail to include national mean trust as a covariate in their models, making it impossible to tell whether the correlation they identify between trust and generalized environmental concern holds across individuals, nations, or both. Not centering lower-level variables by their group means in multilevel models yields coefficient estimates representing weighted averages of the between and within effects, with the weighting unknown (Bell and Jones 2015:137; Raudenbush and Bryk 2002). Across nations, then, Franzen and Vogl identify no statistically significant predictors of generalized concern other than GDP per capita, in contrast to the results I present below. Similarly, Jones, Malesios, and Botetzagias (2009) find that across 24 European countries, an index of social capital, which includes trust, predicts more support for environmental protection-but, like Franzen and Vogl, they do not clarify at which level the association holds. Using an earlier wave of the ISSP, Harring (2013) similarly finds only mixed evidence for a cross-national relationship, perhaps as a consequence of measuring political trust using a question specifically about the quality of the information that government agencies provide on environmental issues.

Among single-nation studies, Meyer and Liebe (2010) report a correlation between trust and support for environmental protection in data from Switzerland, but do not examine political trust. Lubell (2002) reports a correlation between political trust and support for environmental protection, including controlling for both concern and social trust. But that article provides little sense of the strength of the relationship with trust relative to other covariates and relies on data from a small sample of residents around one coastal watershed in the United States. Konisky, Milyo, and Richardson (2008) find mixed evidence for a relationship between political trust and support for environmental protection using only U.S. data.

No previous study, then, has emphasized how much more strongly trust predicts support for environmental protection compared to other factors; none has drawn any attention to a clear, cross-national relationship; none has tested for distinct relationships between social and political trust on the one hand and environmental concern and support for protection on the other; and none has emphasized crossnational differences in the characteristics of individuals who are more supportive of environmental protection. In all these ways, this article adds substantially to what we know about public support for environmental protection. Pampel (2014) is the one study of environmental attitudes that has previously allowed the slopes for individual-level covariates to vary randomly across nations; however, that article 
did so only for variables capturing individuals' socioeconomic status, not those of main interest here. The analyses below, therefore, put multilevel models to more flexible and informative use than any previous study.

\section{Other Explanations of Environmental Concerns and Preferences}

The analyses below control for and simultaneously test a number of influential alternative explanations of support for environmental protection.

First, one alternative perspective holds that environmental concerns and/or support for protection derive from people's overall sociopolitical worldviews. In this view, the environment is a concern of the political left: those who prioritize social equality and welfare over industry and commerce and who are less hierarchical and individualistic. Environmental protection entails interventionist action by the state and, therefore, sits less well with the political right (Borick and Rabe 2010; Gromet, Kunreuther, and Larrick 2013; Hamilton 2011; Kahan et al. 2012; Konisky et al. 2008; Lewandowsky et al. 2013; McCright and Dunlap 2011; McCright, Xiao, and Dunlap 2014; Poortinga et al. 2011; Unsworth and Fielding 2014). Yet all of these articles have examined only U.S. data, with the exception of Poortinga et al. 2011 (who use data from culturally similar Britain) and Unsworth and Fielding (Australia). As such, this perspective is in sore need of testing in a broader range of national contexts. In the one cross-national study of this relationship, using one wave of the World Values Survey, Kvaløy et al. (2012) find that concern about the specific environmental problem of global warming is lower among people who self-identify as right-of-center. They do not, however, clarify whether the relationship holds within countries, among them, or both.

A second perspective treats environmental protection as an expense, and so holds that demand for it-like any other good-should depend on people's incomes (Franzen and Meyer 2010; Henderson 2002). From the perspective of this "prosperity hypothesis," environmental protection is less an issue of collective action and more a luxury, which the wealthy should, therefore, be more willing to purchase (Franzen 2003). Low support for environmental protection, then, reflects that poor people have more important or pressing things to worry about. The argument should hold across countries (with their different levels of national mean income) as well as individuals (with different incomes relative to the country mean). Empirical support for the prosperity thesis is mixed, with analyses based on data from the International Social Survey Programme concluding that environmental concern and support for environmental protection is higher in richer countries and the World Values Surveys and European Values Studies concluding that they are not (Fairbrother 2013; Franzen and Vogl 2013; Gelissen 2007; Givens and Jorgenson 2011; Jorgenson and Givens 2014). At the individual level, those earning higher incomes tend to report higher levels of environmental concern and prioritization, though the effects are not large (see e.g., Fairbrother 2013).

Third, some scholars regard environmental attitudes as tied to a broader shift in people's values, orthogonal to the divide between left and right ideologies and 
subsumable under the label of "postmaterialism." Inglehart (1995; 1997) argued that postmaterialist values arise with rising standards of living, as people are freed from material concerns about their livelihoods and basic security, and can turn their attention instead to higher-level concerns such as freedom and quality of life. Empirically, a number of studies have found that postmaterialist values correlate remarkably strongly with measures of environmental concern and preferences with respect to environmental protection, both across nations (Gelissen 2007) and individuals (Kidd and Lee 1997; Fairbrother 2013).

Aside from testing the relevance of trust, the analyses below also provide assessments of these alternative perspectives. This is true particularly at the international level, because previous research has been able to explain little cross-national variation. In a multilevel analysis of International Social Survey Programme data from 2000, for example, Marquart-Pyatt (2012) does not identify a single country-level variable that is a statistically significant predictor of popular support for environmental protection. This paper, in contrast, identifies correlates of support for environmental protection at both the country and individual levels.

\section{Surveys and Data}

The survey data I analyze below come from the 2010 International Social Survey Programme and the 2007 Pew Research Center's Global Attitudes Project (ISSP Research Group 2012; Pew Research Center 2007). The former surveyed 45,199 respondents in 32 countries and the latter 45,239 in 47; lists of the countries included in each dataset appear in the Online Supplement. Each survey included measures of both environmental concern and respondents' preferences with respect to environmental protection. The ISSP survey mode in 2010 varied by country and in some countries by respondent, though the majority of interviews were face-to-face. The Pew data were collected as part of the Pew Research Center's Global Attitudes Project using telephone and face-to-face interviews.

The ISSP sample is admittedly biased towards high-income democracies, though it also comprises some developing countries (Turkey, South Africa, Philippines), as well as a substantial number of middle-income nations from Latin America and Eastern Europe (e.g., Mexico and Bulgaria). The Pew dataset includes a larger number of lower-income nations, but lacks measures of some key variables. Other widely used datasets, such as the World Values Survey and European Values Studies, also lack important variables-notably, like Pew, political trust. The ISSP is therefore the only extant dataset usable for the purpose of investigating the relationships among environmental concern, preferences with respect to environmental protection, social trust, and political trust.

The samples drawn in eight (low- and middle-income) countries for the Pew survey were also disproportionately or exclusively urban. (See the survey documentation. The results of analyses excluding these countries were substantively the same, so I present results with the full sample.) While the ISSP dataset has been used previously in several social scientific studies of environmental attitudes, the Pew data, however, have not, and I use them for independent validation of 
the results based on the ISSP. I present wordings and descriptive statistics for all questions in the Online Supplement (Tables S1 to S4).

\section{Measures}

Policy experts' preferences notwithstanding, previous studies have found that the public strongly disfavors taxation as a means of addressing environmental problems, even if green taxes tend to be less unpopular than other taxes (Eurobarometer 2011; Jagers and Hammar 2009). Judging by alternative measures, public support for environmental protection is higher: green parties and politicians have been elected and helped form governments in some countries; people are often willing to pay extra for less environmentally damaging goods; and many people join environmental organizations. Yet support for putting a price on pollution and/or resource use remains a powerful measure of normative support for environmental protection, the main outcome of interest here.

In the ISSP dataset, this is captured by questions about the respondent's willingness to pay higher prices and higher taxes for the sake of protecting the environment. In the Pew dataset, the question is whether respondents would prioritize environmental protection even at some economic cost to society. All three questions, then, imply that respondents should consider whether the environment is important enough to them that they would be willing to sacrifice financially for it. In a sense this is misleading, because the point of environmental protection is to solve an economically costly collective action problem, with implications for health, livelihoods, personal security, and broader well-being. Stern (2008) famously makes a strong case for paying the short-term price of reducing greenhouse gas emissions because of the much greater long-term costs of failing to do so. Environmental taxes can also be offset by cuts to other taxes, keeping the net cost neutral or low overall (Prasad 2010). But on the other hand, it is true that measures for environmental protection will typically make some goods and services more costly to consumers, even if the revenues from environmental taxes are recycled to make other goods and services cheaper.

The questions capturing positive environmental concern-people's positive perceptions of the prevalence and seriousness of environmental problems-are diverse. The two in the ISSP dataset and three in the Pew dataset have very different mean values: most people are concerned about the environment generally and consider global warming a serious problem, but few name the environment as a priority issue for their country or one of the greatest threats confronting the world.

The questions about social trust - the belief that one will not be cheated by a typical stranger (Nannestad 2008) - are relatively standard in the literature, even though the two used here differ from each other slightly. The sum of respondents' answers to two questions (one reverse-coded) serve to measure political trust in the ISSP dataset. Goodman and Kruskal's G indicates a rank correlation between these two items of 0.41, making their sum a good index. Substantively, they each capture the respondent's perception that public sector action is typically benevolent rather 
than venal. It should be noted that political trust in the typical country is low: its unweighted mean across all the ISSP respondents is 2.94 on a scale of 0 to 8 .

For measures of left-right ideology, I use respondents' answers to questions about the benefits of free markets, private enterprise, and governments' responsibility to ensure social protection and equality. The two relevant questions in each dataset do not correlate very highly with each other and so appear separately in the analyses below rather than as an index. The ISSP also asked respondents to indicate which political party they identify with, if any. ISSP researchers subsequently coded parties as far left, left/center-left, center/liberal, right/conservative, or far right. See the ISSP documentation for further details. Some party allegiances were coded NA on the left-right scale because their main focus is center versus periphery. In Korea and Russia, ISSP respondents were asked not to name their preferred political party, but to place their political views on a left-right scale; respondents in Israel and Taiwan were not asked about their political preferences at all.

The ISSP measured postmaterialist values by asking respondents to choose from four priority issues and then asking about their second priority. If respondents chose "give people more say in government decisions" and "protect freedom of speech," in either order, they were coded postmaterialist. If they chose "maintain order in the nation" and "fight rising prices" instead, they were coded materialist. If they chose one from each pair, they were coded mixed. (The Pew dataset does not include measures of postmaterialist values, nor left-right party or political identification.)

At the country level, the models I present below include economic development (the log of GDP per capita, from the Penn World Table, version 8.0) as a predictor. Potentially, both trust and cross-national differences in support for state action to address environmental problems could reflect the relative prevalence of untrustworthy behavior in different societies. As a robustness check, then, I tried including Transparency International's Corruption Perceptions Index (CPI), which is based on surveys of experts about the presence of public sector corruption in a country (provided by Dahlberg et al. 2015). I also tried controlling for taxation as a share of GDP using two sources: the Index of Economic Freedom dataset (Heritage Foundation) and the OECD (2015). The OECD data were missing for a number of countries, but, as explained further below, I multiply imputed missing data, and at the country level I included a range of variables that should be informative about taxation, including data on tax policy from the World Bank's World Development Indicators. I divided taxes on income, profits, and capital gains (GC.TAX.YPKG.CN) by GDP (NY.GDP.MKTP.CN).

To assess the relative strengths of the relationships between each covariate and the outcome variable in each model, all right-hand-side variables are standardized (with a mean of 0 and standard deviation of 1), whether at the individual or the country level.

With respect to demographics, in the case of Pew dataset, I recoded education into five categories: primary or less, some secondary, secondary, some postsecondary, and postsecondary. The ISSP, conversely, measured education in years. With respect to income, for each dataset, different national surveys measured income using different bands, and the distribution of income varies substantially from 
country to country. Centering education and income by their country means and standardizing them to have the same standard deviation in every country, however, ensures their comparability.

\section{Analytical Methods}

I fitted multilevel models to observations on survey respondents nested in their countries of residence. With covariates centered at their country means, unlike previous studies, I was able to test for associations both among and within countries simultaneously. That is, the models investigated whether countries with higher levels of each $x$ exhibit more support for environmental protection, and also whether individuals with higher $x$ within a country-relative to the mean-express more support.

Allowing the coefficients on individual-level covariates to vary randomly across countries yields estimates of the average relationship across all countries, taking cross-national variability into account when estimating parameter uncertainty and clarifying how the relationship within each country deviates from that average. (In any given model, however, only a limited number of lower-level variables can be allowed to vary randomly, given limits on the degrees of freedom.) Barr et al. (2003) also point to a technical reason for using them: failing to check the sensitivity of key results to the inclusion of random slopes for a lower-level variable can be anticonservative. Yet, more recently, multilevel models of international survey data have tended to concentrate more on national-level associations rather than differences across countries in individual-level relationships.

I fitted ordinal probit models, of the following general form:

$$
\operatorname{probit}\left(y_{i j}\right)=\beta_{0}+\left(\beta_{1}+u_{1 j}\right) x_{i j 1}+\beta_{2} x_{j 2}+u_{0 j}
$$

where $u_{0 \mathrm{j}} \sim N\left(0, \sigma_{u 0}^{2}\right)$ and $u_{1 \mathrm{j}} \sim N\left(0, \sigma_{u 1}^{2}\right)$. These random intercepts and slopes are modeled with a covariance. Individuals $i=1, \ldots, I$ are nested within countries $j=$ $1, \ldots, J$. Variables subscripted $i$ are properties of individuals, and those subscripted $j$ properties of countries. I estimated the models in a Bayesian framework, with uninformative priors, using the MCMCglmm package in R (Hadfield 2010).

In the results below, rather than presenting frequentist $\mathrm{p}$ values, I therefore note the proportion of the posterior distribution for each beta coefficient lying on the opposite side of zero from the mean estimate. This proportion represents the modeled probability that the parameter has the opposite sign. I report regression coefficients (posterior means) on the probit scale. MCMCglmm parameterizes threshold models such that the probability of observing an outcome in a given category $k$ is: $\operatorname{Pr}(y=k)=F_{N}\left(\gamma_{k} \mid \mathbf{w} \boldsymbol{\theta}, \sigma_{e}^{2}\right)-F_{\mathrm{N}}\left(\gamma_{k+1} \mid \mathbf{w} \boldsymbol{\theta}, \sigma_{e}^{2}\right)$, where $F_{\mathrm{N}}$ is the Normal distribution function; the $\gamma \mathrm{s}$ are cutpoints (with $\gamma_{1}$ equal to zero); $\mathbf{w}$ is a combination of the fixed and random effects design matrices $\mathbf{X}$ and $\mathbf{Z} ; \boldsymbol{\theta}$ is a combination of the parameters $\beta$ and $\mathbf{u}$; and $\sigma_{e}^{2}$ is fixed at 1 . Linear models, treating the outcomes as normally distributed, yielded substantively similar results and appear in the Online Supplement. The Online Supplement also presents the main results with and without random slopes for some key variables. 
I use multilevel multiple imputation to minimize biases as a consequence of missing data-employing the mice package from van Buuren and Groothuis-Oudshoorn (2011). I included all variables, including the dependent variable, in the imputation model, though I did not include observations with a missing $y$ in the analyses. Visual inspection showed good mixing and convergence. Imputations used a heteroskedastic linear two-level model with a Gibbs sampler and rested on the assumption that missingness is random conditional on variables included in the imputation model. I imputed five data sets (using more made no substantive difference), and then combined the MCMC chains that resulted from analyzing each one. Since the imputations were multilevel, they even allowed for the inclusion of observations from countries where entire variables were excluded from the relevant survey. I also report results using listwise deletion in the Online Supplement; substantive conclusions are unchanged.

\section{Results}

This section presents the results first for the correlates of environmental concern, then the correlates of support for environmental protection. Table 1 shows the key features of the models of environmental concern. Other details are provided in Table 1 at the start of the Online Supplement.

In light of the various theoretical perspectives outlined above, some of the results here are as expected. Income correlates positively with concern, though the relationship is weak compared to that with several other covariates, such as education. Respondents with postmaterialist values are also more concerned about environmental problems, though this relationship is only investigable with the one relevant outcome in the ISSP dataset. And concern about the environment is higher among respondents subscribing to a left-of-center political ideology, as captured by questions about income redistribution, the benefits of free enterprise, and political party identification. On the other hand, some relationships are not consistent with expectations. At the country level, residents of more economically developed nations express more concern about the environment by one measure, but not the other three. Respondents in nations expressing more faith in the benefits of free markets are no less concerned about the environment. Most importantly, the relationship between trust- - both social trust and political trust-and environmental concern is highly inconsistent, and in some cases the relationship is negative. Individuals expressing more political trust are, if anything, less rather than more concerned about the environment; concern about global warming is lower in countries with more social trust, and trusting individuals are less likely to name pollution as a problem in their country. Trusting individuals are more concerned about the environment in the ISSP dataset, but the relationship is weak. There is in short no strong or consistent relationship between people's trust and their assessments of the seriousness of environmental problems.

Next, Table 2 presents models of support for environmental protection. All the models in Table 2 are based on ISSP data. The first two columns present models of people's willingness to pay higher prices and higher taxes; the results are similar. At the individual level, income predicts more support for environmental protection, 
Table 1: Models of Positive Environmental Concern

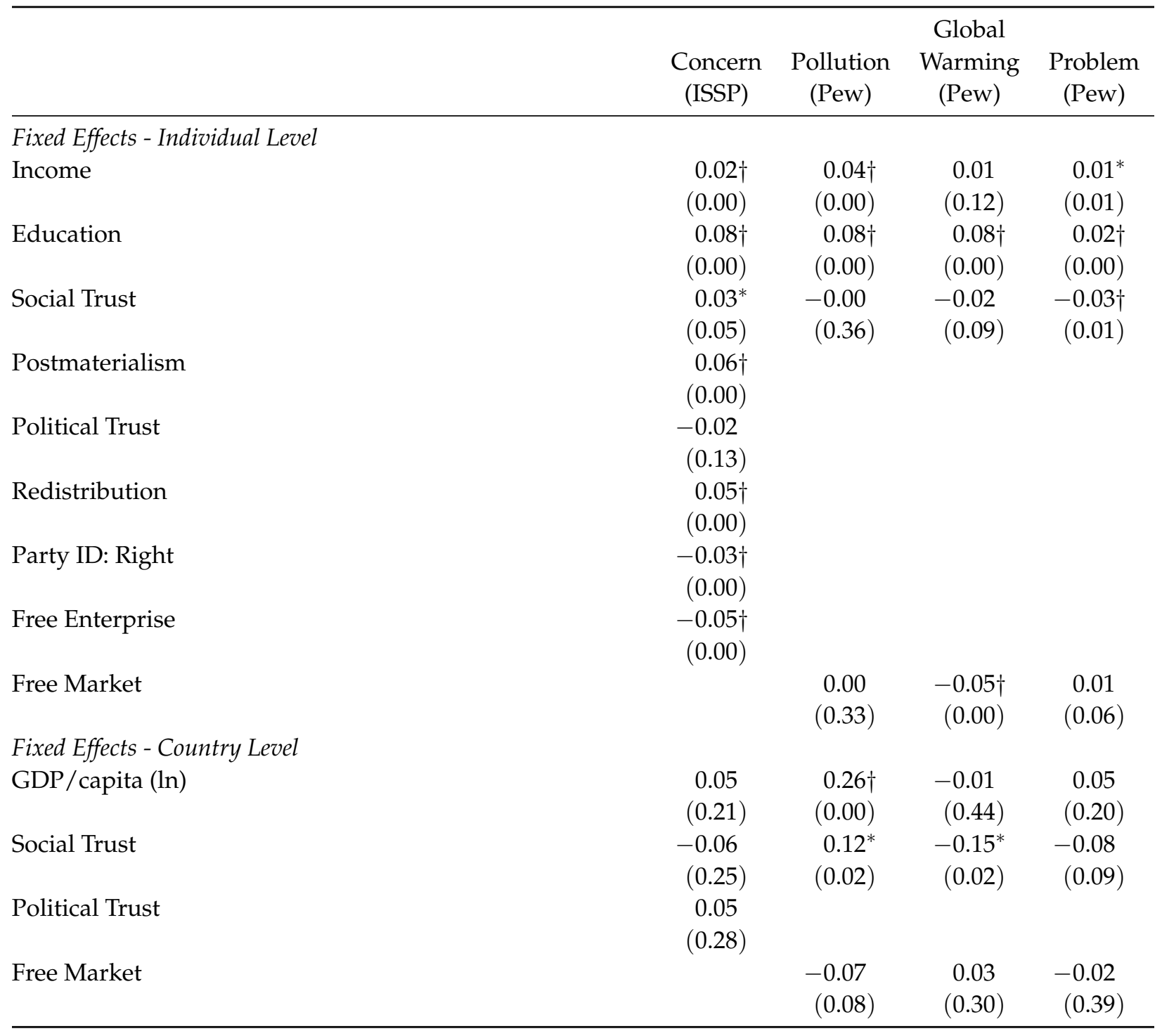

Note: Figures in parentheses are the estimated probabilities of the parameter having the opposite sign; coefficients are marked with * if the probability is less than $0.05, \dagger$ if less than 0.01 . I include Global Warming as an outcome of interest here because, as shown below, it is strongly related to support for environmental protection. Very few respondents provided a positive response for Environmentalism in the ISSP dataset, and so I do not include that here, even though it appears as a covariate in models I present below.

though the magnitude of the effect is small, with education outweighing income, as it did in Table 1 for concern. Here, not surprisingly, concern-now on the right-hand side-predicts greater prioritization of environmental protection at both the individual and country levels. The same is true of postmaterialist values. At the country level, in contrast, postmaterialist values do not, however, predict more support for protection (see model 1 in Table S5). The same holds for country-mean 
education and Party ID (models 2 and 3 in Table S5). GDP per capita and positive concern predict more support for environmental protection.

The important findings here, however, are the magnitudes of the coefficients on social and political trust at the individual level and on political trust at the country level. At both levels, the coefficients on political trust in particular are large. With respect to taxation, at both the individual and country levels, the coefficient for political trust is larger than that for any other variable (aside from positive concern at the individual level). The relative weight of political trust is somewhat lower in the case of paying higher prices (rather than taxes), but it is still quite high at both levels. Social trust does not appear at the country level in Table 2 because it has only a weak relationship with willingness to pay (see model 4 in Table S5 in the Online Supplement). As such, at the country level, it is specifically political trust that matters.

On the other hand, surprisingly, stronger belief in private enterprise correlates with more, not less, support for environmental protection, though the relationship is weak. Being more supportive of income redistribution and identifying with a left party correlate with higher support.

The third model of Table 2 includes individual- and country-level controls for respondents' answers to the question taken as the outcome in the first model: willingness to pay higher prices. The questions about paying higher prices and higher taxes appear one after the other in the ISSP questionnaire, and it would seem likely there would be little to distinguish them. Nevertheless, there are some clear patterns in the results for opinions about taxation, net of opinions about paying higher prices. The country-level covariates no longer correlate with willingness to pay higher taxes, except for GDP per capita-though the correlation is now negative, such that residents of richer countries are more averse to taxation than those of poorer ones. Other than willingness to pay higher prices, again, political trust has the strongest relationship with the outcome. (Unsurprisingly, the coefficients on willingness to pay at both the individual and country levels dwarf all the others.) Model 3 therefore provides evidence that people's openness to environmental protection, specifically using taxation, correlates strongly with their political trust and, to a lesser extent, their social trust.

The fourth model, again of willingness to pay higher taxes as the outcome, includes the same covariates as the second, but different random slopes. The standard deviations of the two random slopes included in this model—for Party ID and support for Free Enterprise-exceed the magnitude of the point estimates of their coefficients, showing there is substantial cross-national heterogeneity in the relationship between each of these variables and the outcome. In contrast, in model 2 , the standard deviations of the random slopes are both smaller than the relevant coefficients (for social and political trust). As such, the relationship between trust and willingness to pay higher taxes is much more consistent across nations. I return to this issue below. Next, Table 3 uses Pew data to validate some of the results from the analyses of the ISSP data reported in Table 2.

Table 3 shows that in the Pew dataset, as in the ISSP dataset, trust has a strong positive relationship with support for environmental protection. And while in some countries the opposite may be true, in the typical case (consistent with results 
Table 2: Models of Support for Environmental Protection (ISSP Data)

\begin{tabular}{|c|c|c|c|c|}
\hline & \multicolumn{4}{|c|}{ — Willing to Pay Higher: —- } \\
\hline & Prices & Tax & Tax & Tax \\
\hline \multicolumn{5}{|c|}{ Fixed Effects - Individual Level } \\
\hline \multirow[t]{2}{*}{ Income } & $0.07 \dagger$ & $0.06 \dagger$ & $0.02 \dagger$ & $0.06 \dagger$ \\
\hline & $(0.00)$ & $(0.00)$ & $(0.00)$ & $(0.00)$ \\
\hline \multirow[t]{2}{*}{ Education } & $0.12 \dagger$ & $0.11 \dagger$ & $0.05 \dagger$ & $0.11 \dagger$ \\
\hline & $(0.00)$ & $(0.00)$ & $(0.00)$ & $(0.00)$ \\
\hline \multirow[t]{2}{*}{ Environmentalism } & $0.08 \dagger$ & $0.08 \dagger$ & $0.04 \dagger$ & $0.08 \dagger$ \\
\hline & $(0.00)$ & $(0.00)$ & $(0.00)$ & $(0.00)$ \\
\hline \multirow[t]{2}{*}{ Concern } & $0.26 \dagger$ & $0.22 \dagger$ & $0.06 \dagger$ & $0.22 \dagger$ \\
\hline & $(0.00)$ & $(0.00)$ & $(0.00)$ & $(0.00)$ \\
\hline \multirow[t]{2}{*}{ Postmaterialism } & $0.08 \dagger$ & $0.07 \dagger$ & $0.03 \dagger$ & $0.07 \dagger$ \\
\hline & $(0.00)$ & $(0.00)$ & $(0.00)$ & $(0.00)$ \\
\hline \multirow{2}{*}{ Social Trust } & $0.07 \dagger$ & $0.08 \dagger$ & $0.05 \dagger$ & $0.09 \dagger$ \\
\hline & $(0.00)$ & $(0.00)$ & $(0.00)$ & $(0.00)$ \\
\hline \multirow[t]{2}{*}{ Political Trust } & $0.11 \dagger$ & $0.15 \dagger$ & $0.11 \dagger$ & $0.15 \dagger$ \\
\hline & $(0.00)$ & $(0.00)$ & $(0.00)$ & $(0.00)$ \\
\hline \multirow[t]{2}{*}{ Redistribution } & 0.00 & $0.02 \dagger$ & $0.03 \dagger$ & $0.02 \dagger$ \\
\hline & $(0.31)$ & $(0.00)$ & $(0.00)$ & $(0.00)$ \\
\hline \multirow[t]{2}{*}{ Party ID: Right } & $-0.01 \dagger$ & $-0.03 \dagger$ & $-0.03 \dagger$ & $-0.03^{*}$ \\
\hline & $(0.01)$ & $(0.00)$ & $(0.00)$ & $(0.00)$ \\
\hline \multirow[t]{2}{*}{ Free Enterprise } & $0.03 \dagger$ & $0.01^{*}$ & $-0.01^{*}$ & 0.02 \\
\hline & $(0.00)$ & $(0.02)$ & $(0.02)$ & $(0.08)$ \\
\hline \multirow[t]{2}{*}{ Willing to Pay } & & & $1.06 \dagger$ & \\
\hline & & & $(0.00)$ & \\
\hline \multicolumn{5}{|l|}{ Fixed Effects - Country Level } \\
\hline \multirow[t]{2}{*}{ GDP per capita $(\ln )$} & $0.17 \dagger$ & $0.11 \dagger$ & $-0.08 \dagger$ & 0.04 \\
\hline & $(0.00)$ & $(0.00)$ & $(0.00)$ & $(0.23)$ \\
\hline \multirow[t]{2}{*}{ Concern } & $0.12 \dagger$ & $0.08^{*}$ & $-0.05^{*}$ & 0.07 \\
\hline & $(0.00)$ & $(0.01)$ & $(0.04)$ & $(0.05)$ \\
\hline \multirow[t]{2}{*}{ Political Trust } & $0.11 \dagger$ & $0.12 \dagger$ & 0.01 & $0.13^{*}$ \\
\hline & $(0.00)$ & $(0.00)$ & $(0.40)$ & $(0.02)$ \\
\hline \multirow[t]{2}{*}{ Willing to Pay } & & & $0.42 \dagger$ & \\
\hline & & & $(0.00)$ & \\
\hline \multicolumn{5}{|c|}{ Random Effects Standard Deviations } \\
\hline Country (Intercepts) & 0.23 & 0.23 & 0.12 & 0.24 \\
\hline Social Trust (Slopes) & 0.06 & 0.06 & 0.04 & \\
\hline Political Trust (Slopes) & 0.05 & 0.05 & 0.04 & \\
\hline Party ID: Right (Slopes) & & & & 0.06 \\
\hline Free Enterprise (Slopes) & & & & 0.06 \\
\hline
\end{tabular}

Note: Figures in parentheses are the estimated probabilities of the parameter having the opposite sign; coefficients are marked with * if the probability is less than $0.05, \dagger$ if less than 0.01 . Covariances between intercepts and slopes are also estimated, but not reported. Other details are provided in Table 2 at the start of the Online Supplement. 
Table 3: Correlates of Support for Environmental Protection (Pew Data)

\begin{tabular}{lc}
\hline & Priority \\
\hline Fixed Effects - Individual Level & -0.01 \\
Income & $(0.10)$ \\
& $0.04 \dagger$ \\
Education & $(0.00)$ \\
& $0.07 \dagger$ \\
Pollution & $(0.00)$ \\
& $0.08 \dagger$ \\
Global Warming & $(0.00)$ \\
Problem & $0.14 \dagger$ \\
Social Trust & $(0.00)$ \\
Care & $0.13 \dagger$ \\
Free Market & $(0.00)$ \\
& $0.10 \dagger$ \\
Fixed Effects - Country Level & $(0.00)$ \\
Global Warming & $0.15 \dagger$ \\
Free Market & $(0.00)$ \\
& \\
\hline
\end{tabular}

Note: Figures in parentheses are the estimated probabilities of the parameter having the opposite sign; coefficients are marked with * if the probability is less than $0.05, \dagger$ if less than 0.01 . Other details are provided in Table 3 at the start of the Online Supplement.

from the ISSP) believing in the benefits of free markets predicts more support for environmental protection, not less, and at both levels. This finding contradicts the view that environmentalism is inherently more consistent with a left- rather than right-of-center political worldview. Also consistent with the results from the ISSP data, Table 3 shows that education trumps income as a demographic predictor of support for environmental protection. I included as broad a range of controls for environmental concern here as possible (Pollution, Global Warming, Problem).

As a robustness check, I tried adding to the second model in Table 2 a nationallevel control for taxation as a share of GDP. The ISSP dataset asks about paying higher taxes than at present, and perhaps people's answers could be affected by the existing level of taxation in their country: residents of countries where taxes are higher may be less willing to pay still more. I also tried including a control for corruption, as captured by Transparency International's Corruption Perceptions Index. The CPI is based on surveys of businesspeople, risk analysts, and the general public, and ranges between 10 (highly clean) and 0 (highly corrupt). Including 
these controls made no substantive difference; the strength of the relationships between trust and the outcomes in Table 2 also did not change appreciably in models fitted without including measures of concern as controls (see Table S7 in the Online Supplement). Finally, there are no significant interaction effects between (individuals') political trust and either concern or party identification (see Table S8). Political trust is not, in that sense, what "converts" environmental concern into support for action-rather, it is a separate influence. Including only one of social or political trust in these model, rather than both, does not make any notable difference.

Figure 1 presents the relative magnitudes of the effects in model 2 of Table 2 and also shows their robustness. Coefficients (for standardized and, therefore, comparable variables) appear with $95 \%$ Bayesian credible intervals. The figure presents both ordinal models with multiple imputation for missing observations on right-hand side variables and linear models with listwise deletion. Technically, comparing the magnitudes of different coefficients in a probit model is problematic (see Mood 2010). But Figure 1 shows that the results from linear models-in which comparing different coefficients is unproblematic-are very similar. In each case, the coefficients represent the expected effect of a 1 standard deviation change in each covariate, whether at the country or individual level.

As discussed earlier, the magnitudes of some random slope variances indicate substantial heterogeneity in key relationships. Next, then, I show how they vary cross-nationally. Figure 2 presents country-specific relationships between political and social trust and willingness to pay higher taxes. The relationships vary, given that the model estimates separate slopes for each country.

Figure 3 is derived from model 4 in Table 2 using the same data and same model as Figure 2, but with different coefficients allowed to vary randomly. Here the coefficients on Party ID and support for Free Enterprise vary by country.

The relationships in Figure 3 are much more variable than those in Figure 2, with support for Free Enterprise predicting less support for environmental protection in some countries (where the lines slope downwards, as in Norway and the United States), but stronger support in others (Germany and the Philippines). Similarly, people identifying with a right-of-center party are much less supportive of environmental protection in some countries (Sweden, United States), while in others they are more so (Russia) — in one case, substantially so (Mexico). The (admittedly very few) developing countries represented in Figure 3 do not appear particularly distinct from richer countries, especially relative to the marked variation across countries within the developed world. The former state socialist nations of Central and Eastern Europe constitute a more distinct grouping, as previous studies have noted (e.g., Chaisty and Whitefield 2015). These countries do not appear a category apart, however, in Figure 2.

Figures 2 and 3 therefore show how much more consistently trust predicts support for environmental protection compared to political ideology. They also show that the much-studied case of the United States is not exceptional, but also far from universal; many countries are very different. The Online Supplement also includes country-specific estimates of the slopes for Free Enterprise, Party ID, and Free Market based on probit models fitted to each country separately (Tables S9, S10, 


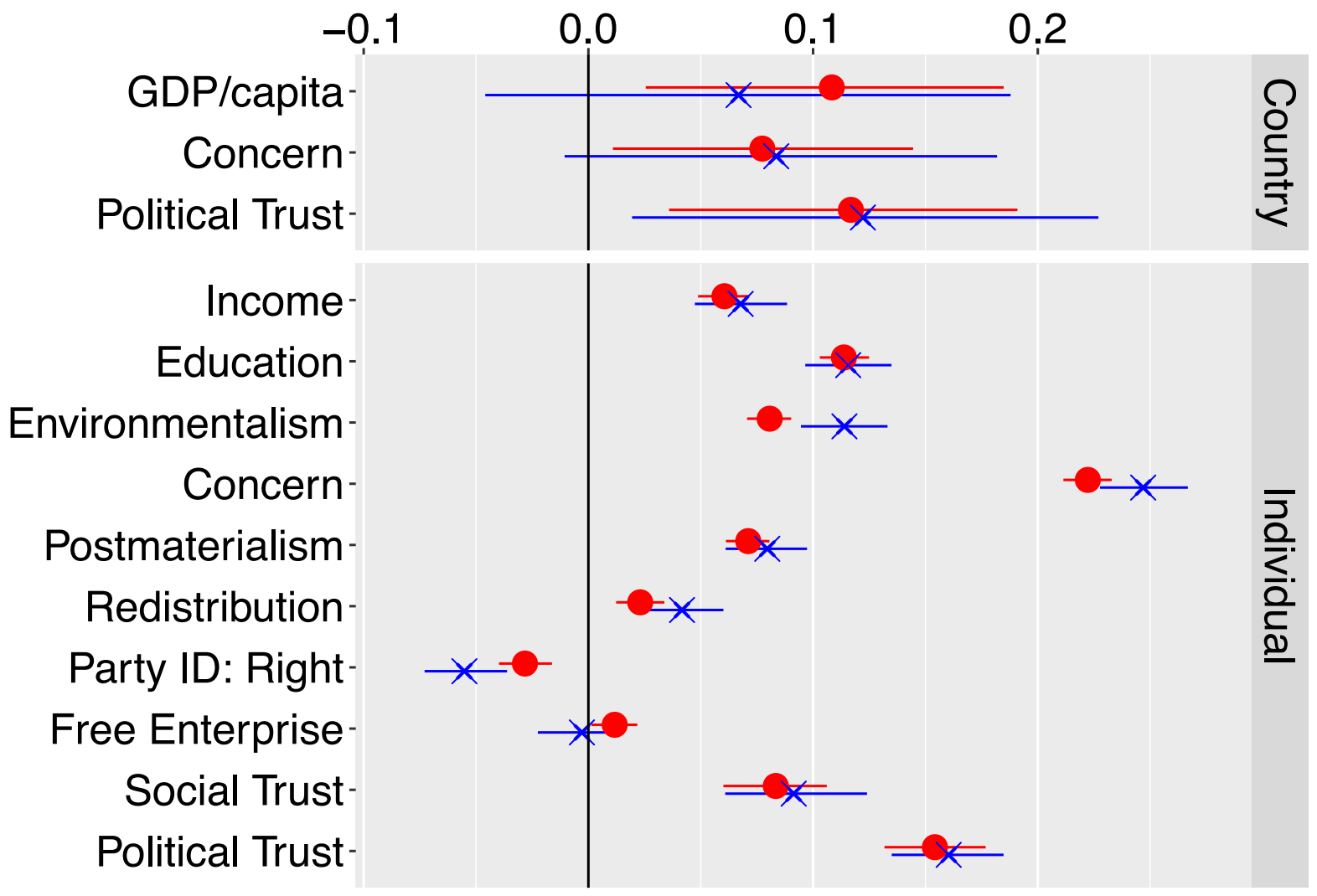

Figure 1: Coefficients from Table 2, model 2 (Fitted Two Ways).

Note: The figure shows the expected effect of a 1 standard deviation change in each $\mathrm{x}$ (with $95 \%$ Bayesian credible intervals). Dots represent estimates from ordinal probit models, with multiple imputations for missing data. X's represent estimates from linear models, with listwise deletion for missing data. Similar graphical representations of all other models presented in Tables 1,2, and 3 are included in the Online Supplement.

and S11). These also show how the slopes can be positive or negative depending on the country, and how the majority of the slopes for Free Enterprise (ISSP) and Free Market (Pew) are positive, not negative. Additional models in the Online Supplement also show that the coefficients on Free Enterprise are positive even in models without other similar covariates (for support for Redistribution and Party ID, see Table S7).

\section{Discussion and Conclusions}

This paper has shown that people who are trusting are more supportive of environmental protection, and not because they believe environmental problems are any more serious than people who are not trusting. In the world as a whole, moreover, the importance of trust far surpasses that of political ideology; the environment is a left-right issue in some countries, but in many it is not. The overestimation of 

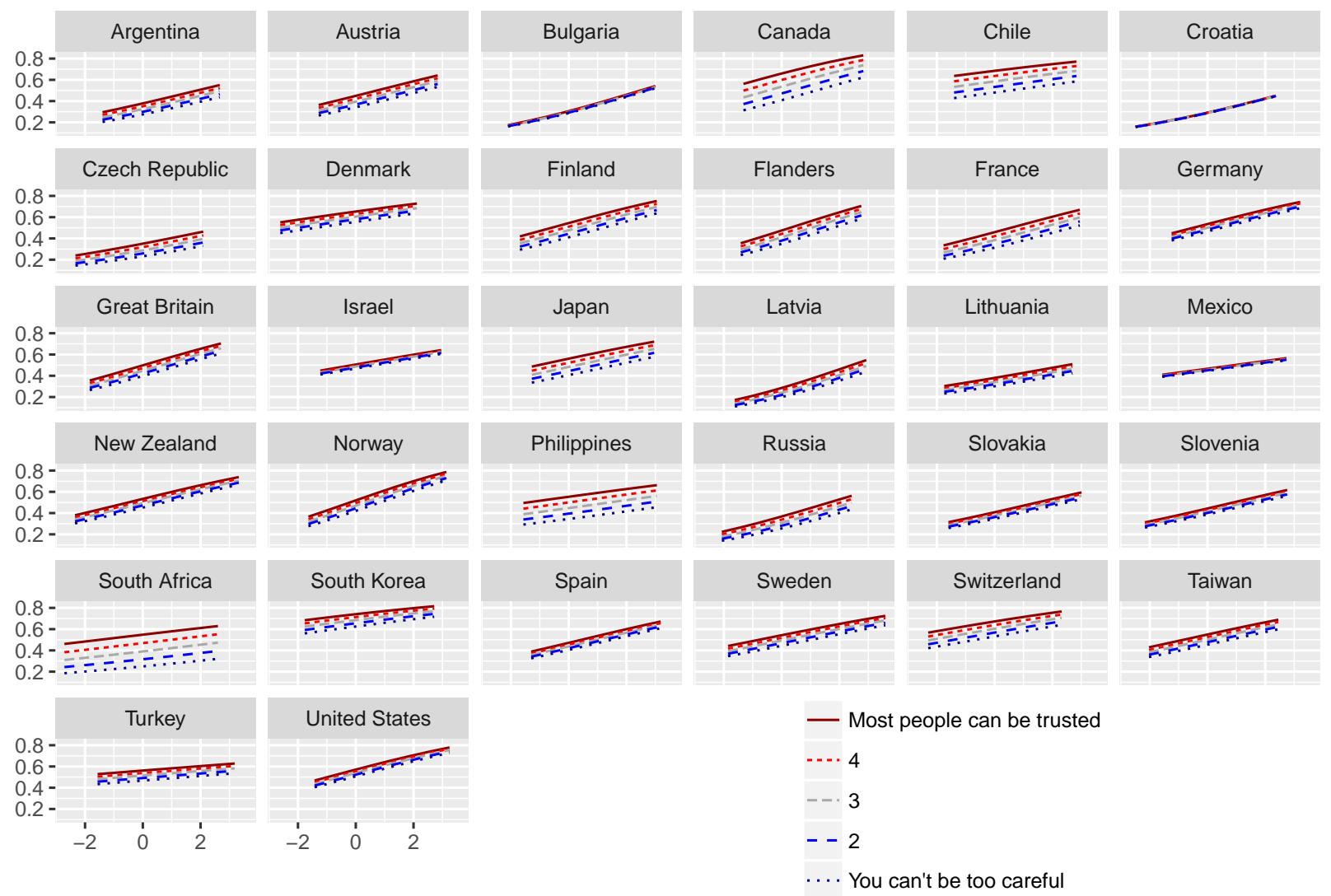

Figure 2: Trust and support for environmental protection by country.

Note: The lines represent the modeled probability of falling into the highest three response categories on the five-point scale based on model 2 in Table 2. The horizontal axis represents political trust, and the different lines social trust (solid lines represent those with the most trust). In countries with lines that are further apart, support for environmental protection is more strongly associated with social trust; in countries where the lines are steeper, protection is more strongly associated with political trust.

ideology's importance may be due to over-extrapolation from studies of the United States, an atypical political context. Fankhauser, Gennaioli, and Collins (2015) find, for example, that only in Anglo-Saxon countries is there much evidence that parties on the left make more legislative efforts to address climate change than those on the right.

In practical terms, if policymakers or environmental advocates could manipulate just one correlate, which would spur the biggest rise in public support for environmental protection? The OECD (2006) recommends policymakers build public support for environmental taxes by increasing people's awareness of the problems that such taxes are meant to address. Do the analyses here support such a recommendation? At the risk of an overly causal interpretation of the analyses above, we can investigate the extent to which each variable is a constraint on public support for environmental protection by comparing counterfactual scenarios wherein each individual- or country-level covariate were set at its maximum, holding all others at their observed values. Based on the models in Table 2, the probability 


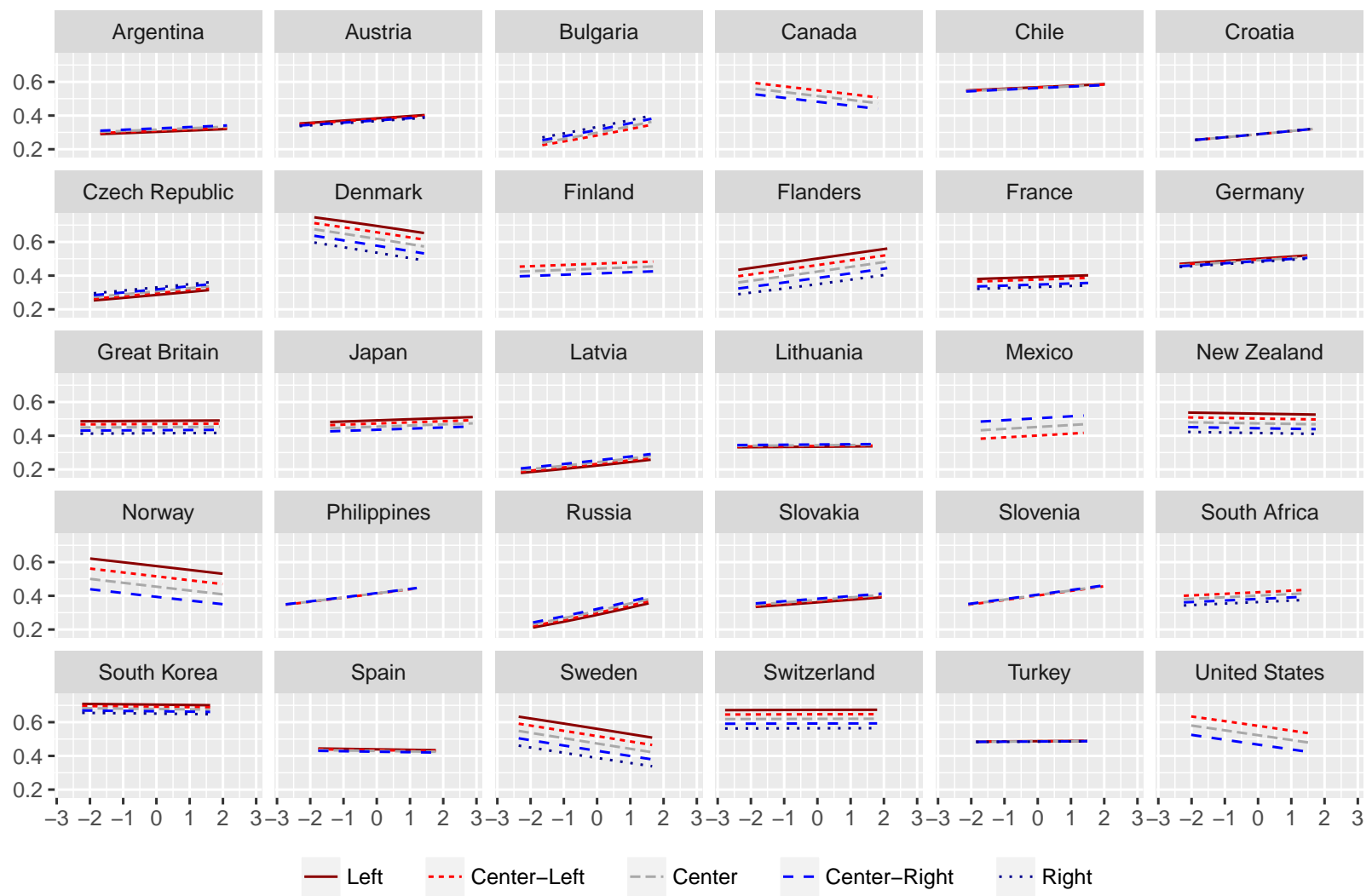

Figure 3: Ideology and support for environmental protection by country.

Note: The lines represent the modeled probability of falling into the highest three response categories on the five-point scale based on model 4 in Table 2. Taiwan and Israel are excluded because the surveys in those countries did not ask about party identification. The horizontal axis represents belief in Free Enterprise, and the different lines identification with right, center-right, center, center-left, and left parties. (Solid lines show the left.)

of a respondent in the average country falling into the top three answer categories would be 0.54 if everyone had maximal concern, 0.62 if everyone had the highest level of education, 0.60 if everyone had maximal political trust, and 0.50 if everyone had maximal social trust. By comparison, the probabilities would be only 0.45 if everyone were a maximal believer in Redistribution, 0.43 if everyone's Party ID were maximally Left, and 0.43 if they all believed in Free Enterprise.

These counterfactual probabilities reflect both the difference between each variable's observed and hypothetically maximal value and the strength of its relationship with people's support for environmental protection. They suggest the OECD's recommendation is dubious. Most people already accept the reality and seriousness of environmental problems; not that many more could become so convinced. In contrast, many could become more trusting and open to effective policy solutions. Fostering further concern is therefore unlikely to make as much difference to public support as increasing people's confidence that environmental policies will be effective and implemented as promised. 


\section{References}

Baird, Julia. 2014. "Why Australia Killed Its Carbon Tax." The New York Times. Page A27, July 24.

Barr, Dale J., Roger Levy, Christoph Scheepers, and Harry J. Tily. 2013. "Random Effects Structure for Confirmatory Hypothesis Testing: Keep it Maximal." Journal of Memory and Language 68:255-278. http://dx.doi .org/10.1016/j · jml .2012.11.001

Bell, Andrew, and Kelvyn Jones. 2015. "Explaining Fixed Effects: Random Effects Modeling of Time-Series Cross-Sectional and Panel Data." Political Science Research and Methods 3:133-153. http://dx.doi.org/10.1017/psrm. 2014.7

Borick, Christopher P., and Barry G. Rabe. 2010. "A Reason to Believe: Examining the Factors that Determine Individual Views on Global Warming." Social Science Quarterly 91:777-800. http://dx.doi.org/10.1111/j.1540-6237.2010.00719.x

Cao, Xun, Helen V. Milner, Aseem Prakash and Hugh Ward. 2014. "Research Frontiers in Comparative and International Environmental Politics: An Introduction." Comparative Political Studies 47:291-308. http://dx.doi .org/10.1177/0010414013509567

Chaisty, Paul, and Stephen Whitefield. 2015. "Attitudes Towards the Environment: Are Post-Communist Societies (Still) Different?" Environmental Politics 24:598-616. http://dx . doi.org/10.1080/09644016.2015.1023575

Dahlberg, Stefan, Sören Holmberg, Bo Rothstein, Felix Hartmann \& Richard Svensson. 2015. The Quality of Government Basic Dataset, version Jan15. University of Gothenburg: The Quality of Government Institute, http://www.qog.pol.gu.se.

Dresner, Simon, Louise Dunne, Peter Clinch, and Christiane Beuermann. 2006. "Social and Political Responses to Ecological Tax Reform in Europe: An Introduction to the Special Issue." Energy Policy 34:895-904. http: //dx . doi .org/10.1016/j . enpol .2004.08.043

Dunlap, Riley E., and Richard York. 2008. "The Globalization of Environmental Concern and the Limits of the Postmaterialist Values Explanation: Evidence from Four Multinational Surveys." The Sociological Quarterly 49:529-563. http://dx.doi .org/10.1111/j . $1533-8525.2008 .00127 . x$

Dunlap, Riley E., and Robert E. Jones. 2002. "Environmental Concern: Conceptual and Measurement Issues." Pp. 482-524 in Handbook of Environmental Sociology, edited by R.E. Dunlap and W. Michelson. Westport, CT: Greenwood Press.

Endres, Alfred. 2011. Environmental Economics: Theory and Policy. New York: Cambridge University Press.

Eurobarometer. 2011. "Attitudes of European citizens towards the environment." Special Eurobarometer 365 / Wave 75.2. http://ec.europa.eu/public_opinion/archives/ eb_special_379_360_en.htm.

Fairbrother, Malcolm. 2013. "Rich People, Poor People, and Environmental Concern: Evidence across Nations and Time." European Sociological Review 29:910-922. http: //dx.doi.org/10.1093/esr/jcs068

Fankhauser, Sam, Caterina Gennaioli, and Murray Collins. 2015. "The Political Economy of Passing Climate Change Legislation: Evidence from a Survey." Global Environmental Change 35:52-61. http://dx.doi .org/10.1016/j.gloenvcha. 2015.08.008

Farrell, Justin. 2016. "Corporate Funding and Ideological Polarization about Climate Change." Proceedings of the National Academy of Sciences 113:92-97. http: //dx. doi .org/ 10.1073/pnas. 1509433112 
Franzen, Axel, and Dominikus Vogl. 2013. "Two Decades of Measuring Environmental Attitudes: A Comparative Analysis of 33 Countries." Global Environmental Change 23:10011008. http://dx.doi.org/10.1016/j.gloenvcha.2013.03.009

Franzen, Axel, and Reto Meyer. 2010. "Environmental Attitudes in Cross-National Perspective: A Multilevel Analysis of the ISSP 1993 and 2000." European Sociological Review 26:219-234. http://dx.doi.org/10.1093/esr/jcp018

Gelissen, John. 2007. "Explaining Popular Support for Environmental Protection: A Multilevel Analysis of 50 Nations." Environment and Behavior 39:392-415. http://dx. doi .org/ 10.1177/0013916506292014

Givens, Jennifer E., and Andrew K. Jorgenson. 2013. "Individual Environmental Concern in the World Polity: A Multilevel Analysis." Social Science Research 42:418-431. http: //dx.doi.org/10.1016/j.ssresearch.2012.10.005

Green Fiscal Commission. 2009. "Public Opinion on a Green Tax Shift." Available: http://www.greenfiscalcommission.org.uk/images/uploads/GFC_Briefing_ 3_Final.pdf. Briefing Paper Three.

Gromet, Dena M., Howard Kunreuther, and Richard P. Larrick. 2013. "Political Ideology Affects Energy-Efficiency Attitudes and Choices." Proceedings of the National Academy of Sciences 110:9314-9319. http://dx.doi.org/10.1073/pnas.1218453110

Hadfield, Jarrod. 2010. "MCMC Methods for Multi-Response Generalised Linear Mixed Models: The MCMCglmm R Package." Journal of Statistical Software 33:1-22. http://dx . doi.org/10.18637/jss.v033.i02

Hamilton, Lawrence C. 2011. "Education, Politics and Opinions about Climate Change: Evidence for Interaction Effects." Climatic Change 104:231-242. http://dx . doi .org/10. 1007/s10584-010-9957-8

Harring, Niklas. 2013. "Understanding the Effects of Corruption and Political Trust on Willingness to Make Economic Sacrifices for Environmental Protection in a CrossNational Perspective." Social Science Quarterly 94:660-671. http://dx . doi .org/10.1111/ j.1540-6237.2012.00904.x

Harrison, Kathryn. 2010. "The Comparative Politics of Carbon Taxation." Annual Review of Law and Society 6:507-29. http: //dx.doi .org/10.1146/annurev . lawsocsci . 093008. 131545

Harrison, Kathryn. 2012. "A Tale of Two Taxes: The Fate of Environmental Tax Reform in Canada." Review of Policy Research 29:383-407. http://dx.doi .org/10.1111/ j.1541-1338.2012.00565.x

Heritage Foundation. 2015. Index of Economic Freedom dataset. Available: http://www . heritage.org/index/explore?view=by-variables.

Irwin, Kyle, and Nick Berigan. 2013. "Trust, Culture, and Cooperation: A Social Dilemma Analysis of Pro-Environmental Behaviors." The Sociological Quarterly 54:424-449. http: //dx.doi.org/10.1111/tsq. 12029

ISSP Research Group. 2012. International Social Survey Programme: Environment III - ISSP 2010. GESIS Data Archive, Cologne. ZA5500 Data file Version 2.0.0, doi:10.4232/1.11418

Jagers, Sverker C., and Henrik Hammar. 2009. "Environmental Taxation for Good and for Bad: The Efficiency and Legitimacy of Sweden's Carbon Tax." Environmental Politics 18:218-237. http://dx.doi.org/10.1080/09644010802682601

Jones, Nikoleta, Chrisovaladis Malesios, and Iosif Botetzagias. 2009. "The Influence of Social Capital on Willingness to Pay for the Environment among European Citizens." European Societies 11:511-530 http://dx.doi.org/10.1080/14616690802624168 
Jorgenson, Andrew K., and Jennifer E. Givens. 2014. "Economic Globalization and Environmental Concern: A Multilevel Analysis of Individuals Within 37 Nations." Environment and Behavior 46:848-871. http: //dx.doi.org/10.1177/0013916513479796

Kahan, Dan M., Ellen Peters, Maggie Wittlin, Paul Slovic, Lisa Larrimore Ouellette, Donald Braman, and Gregory N. Mandel. 2012. "The Polarizing Impact of Science Literacy and Numeracy on Perceived Climate Change Risks." Nature Climate Change 2:732-735. http://dx.doi.org/10.1038/nclimate1547

Kidd, Quentin, and Aie-Rie Lee. 1997. "Postmaterialist Values and the Environment: A Critique and Reappraisal." Social Science Quarterly 78:1-15.

Konisky, David M., Jeffrey Milyo, and Lilliard E. Richardson, Jr. 2008. "Environmental Policy Attitudes: Issues, Geographical Scale, and Political Trust." Social Science Quarterly 89:1066-1085. http://dx.doi.org/10.1111/j.1540-6237.2008.00574.x

Kvaløy, Berit, Henning Finseraas, and Ola Listhaug. 2012. "The Publics' Concern for Global Warming: A Cross-National Study of 47 Countries." Journal of Peace Research 49:11-22. http://dx.doi.org/10.1177/0022343311425841

Lewandowsky, Stephan, Gilles E. Gignac, and Klaus Oberauer. 2013. "The Role of Conspiracist Ideation and Worldviews in Predicting Rejection of Science." PLoS ONE 8:e75637. http://dx.doi.org/10.1371/journal. pone.0075637

Lorenzoni, Irene, Sophie Nicholson-Cole, Lorraine Whitmarsh. 2007. "Barriers Perceived to Engaging with Climate Change Among the UK Public and their Policy Implications." Global Environmental Change 17:445-459. http://dx.doi.org/10.1016/j.gloenvcha. 2007.01 .004

Lubell, Mark. 2002. "Environmental Activism as Collective Action." Environment and Behavior 34:431-454. http://dx.doi.org/10.1177/00116502034004002

Maclucas, Neil. "Green Fiasco: 92\% Of Swiss Voters Reject Carbon Tax In Referendum." The Wall Street Journal. 8 March.

Marien, Sofie, and Marc Hooghe. 2011. "Does Political Trust Matter? An Empirical Investigation into the Relation between Political Trust and Support for Law Compliance." European Journal of Political Research 50:267-291. http://dx. doi .org/10.1111/j.1475-6765.2010. 01930.x

Marquart-Pyatt, Sandra T. 2012. "Contextual Influences on Environmental Concerns CrossNationally: A Multilevel Investigation." Social Science Research 41:1085-1099. http://dx . doi.org/10.1016/j.ssresearch.2012.04.003

McCright, Aaron M., and Riley E. Dunlap. 2011. "Cool Dudes: The Denial of Climate Change among Conservative White Males in the United States." Global Environmental Change 21:1163-1172. http://dx.doi.org/10.1016/j.gloenvcha.2011.06.003

McCright, Aaron M., Chenyang Xiao, and Riley E. Dunlap. 2014. "Political Polarization on Support for Government Spending on Environmental Protection in the USA, 19742012." Social Science Research 48:251-260. http://dx.doi.org/10.1016/j.ssresearch . 2014.06 .008

Meyer, Reto, and Ulf Liebe. 2010. "Are the Affluent Prepared to Pay for the Planet? Explaining Willingness to Pay for Public and Quasi-Private Environmental Goods in Switzerland." Population and Environment 32:42-65. http://dx . doi .org/10.1007/s11111-010-0116-y

Mood, Carina. 2010. "Logistic Regression: Why We Can not Do What We Think We Can Do, and What We Can Do About It." European Sociological Review 26:67-82. http: //dx. doi. org/10.1093/esr/jcp006 
Nannestad, Peter. 2008. "What Have We Learned About Generalized Trust, If anything?" Annual Review of Political Science 11:413-36. http://dx.doi.org/10.1146/annurev . polisci.11.060606.135412

OECD. 2006. The Political Economy of Environmentally Related Taxes. Paris: Organisation for Economic Co-operation and Development.

OECD. 2010. Taxation, Innovation and the Environment. Paris: Organisation for Economic Cooperation and Development.

OECD. 2015. OECD Stat Extracts. Available: http://stats.oecd.org/index.aspx? DataSetCode=REV.

Ostrom, Elinor. 1999. "Coping with Tragedies of the Commons." Annual Review of Political Science 2:493-535. http://dx.doi.org/10.1146/annurev .polisci.2.1.493

Ostrom, Elinor. 2010. "Polycentric Systems for Coping with Collective Action and Global Environmental Change." Global Environmental Change 20:550-557. http: //dx . doi .org/ 10.1016/j.gloenvcha.2010.07.004

Pampel, Fred C. 2014. "The Varied Influence of SES on Environmental Concern." Social Science Quarterly 95:57-75. http://dx.doi.org/10.1111/ssqu.12045

Parry, Ian W.H., John Norregaard, and Dirk Heine. 2012. "Environmental Tax Reform: Principles from Theory and Practice." Annual Review of Resource Economics 4:101-283. http://dx.doi.org/10.1146/annurev-resource-110811-114509

Pearce, D. 2002. "An Intellectual History of Environmental Economics." Annual Review of Energy and the Environment 27:57-81. http://dx . doi .org/10.1146/annurev . energy . 27 . 122001.083429

Pew Research Center. 2007. Pew Global Attitudes Project: Spring 2007 Survey of 47 Publics.

Prasad, Monica. 2010. "Taxation as a Regulatory Tool: Lessons from Environmental Taxes in Europe." Pp. 362-390 in Government and Markets: Toward a New Theory of Regulation, edited by E.J. Balleisen and D.A. Moss. New York: Cambridge University Press.

Raudenbush, Stephen W. and Anthony S. Bryk. 2002. Hierarchical Linear Models: Applications and Data Analysis Methods. 2nd ed. London: Sage.

Scholz, John T., and Mark Lubell. 1998. "Trust and Taxpaying: Testing the Heuristic Approach to Collective Action." American Journal of Political Science 42:398-417. http: //dx . doi .org/ $10.2307 / 2991764$

Solomon, Susan. 2004. "The Hole Truth: What's News (and What's Not) about the Ozone Hole." Nature 427:289-291. http://dx.doi .org/10.1038/427289a

Sønderskov, Kim Mannemar. 2009. "Different Goods, Different Effects: Exploring the Effects of Generalized Social Trust in Large-N Collective Action." Public Choice 140:145-160. http://dx.doi.org/10.1007/s11127-009-9416-0

Stern, Nicholas. 2008. "The Economics of Climate Change." American Economic Review: Papers $\mathcal{E}$ Proceedings 98:1-37. http://dx.doi.org/10.1257/aer.98.2.1

Thalmann, Philippe. 2004. "The Public Acceptance of Green Taxes: 2 Million Voters Express their Opinion." Public Choice 119:179-217. http://dx.doi.org/10.1023/B: PUCH.0000024165.18082.db

Thomas Dietz, Gerald T. Gardner, Jonathan Gilligan, Paul C. Stern, and Michael P. Vandenbergh. 2009. "Household Actions Can Provide a Behavioral Wedge to Rapidly Reduce US Carbon Emissions." Proceedings of the National Academy of Sciences 106:18452-18456. http://dx.doi.org/10.1073/pnas.0908738106 
Transparency International. 2010. The Corruption Perceptions Index (http://www . transparency.org/cpi2014). Provided by the Quality of Government database, Dahlberg et al. http://www.qogdata.pol.gu.se/data/qog_bas_ts_jan15.csv.

UNEP. 2004. The Use of Economic Instruments in Environmental Policy: Opportunities and Challenges. Geneva: United Nations Environment Programme.

Unsworth, Kerrie L., and Kelly S. Fielding. 2014. "It's Political: How the Salience of One's Political Identity Changes Climate Change Beliefs and Policy Support." Global Environmental Change 27:131-137. http: //dx.doi.org/10.1016/j.gloenvcha.2014.05.002

Van Buuren, Stef, and Groothuis-Oudshoorn. 2011. "Mice: Multivariate Imputation by Chained Equations in R." Journal of Statistical Software 45. http: //dx . doi . org/10.18637/ jss.v045.i03.

World Bank. 2013. World Development Indicators. Accessed using Vincent Arel-Bundock, WDI: World Development Indicators (World Bank). R package version 2.4. http: //CRAN . R-project.org/package=WDI.

Wouter Poortinga, Alexa Spence, Lorraine Whitmarsh, Stuart Capstick, and Nick F. Pidgeon. 2011. "Uncertain Climate: An Investigation into Public Scepticism about Anthropogenic Climate Change." Global Environmental Change 21:1015-1024. http://dx.doi.org/10. 1016/j.gloenvcha.2011.03.001

Acknowledgements: The author thanks Diego Miralles, Laura De Vito, Jan Mewes, and Jonas Edlund for helpful comments on earlier versions of this article, and audiences at the Institute for Futures Studies (Stockholm), Umeå University, Örebro University, Gothenburg University, Stockholm University, and the Institute for Social and Economic Research (Essex) for many constructive suggestions and criticisms. The research on which the article is based was funded in part by the Riksbankens Jubileumsfonds (Swedish Foundation for Humanities and Social Sciences, project number NHS142035:1), and a Fellowship from the Institute for Advanced Studies at the University of Bristol.

Malcolm Fairbrother: School of Geographical Sciences, Cabot Institute, Centre for Multilevel Modelling, University of Bristol. E-mail: ggmhf@bristol.ac.uk. 